\title{
COMPARISON OF PARTICLE SIZE AND SHAPE DISTRIBUTION OF CORUNDUM PRODUCED BY INDUSTRIAL BALL MILL AND MATERIAL BED COMPRESSION
}

\author{
László Tamás \\ PhD student, University of Miskolc \\ Institute of Raw Material Preparation and Environmental Processing, \\ 3515 Miskolc, Miskolc-Egyetemváros, email: tamaslaszlo93@gmail.com \\ development engineer, Refra-System Ltd. \\ 9200 Ujrónafö, Császárrét Major 10. \\ Ádám Rácz \\ associate professor, University of Miskolc \\ Institute of Raw Material Preparation and Environmental Processing, \\ Address: 3515, Miskolc, Miskolc-Egyetemváros, email: ejtracz@uni-miskolc.hu
}

\begin{abstract}
Comminution of corundum is a challenging task, as it has very high hardness and compression strength, and it is also a very abrasive material. Selection of the best comminution process for each particle size thus has a great importance. But for this, first we must understand the effects of different type of stresses and comminution methods used for the dry comminution of corundum. In this article the comparison of particle size and shape distribution of corundum produced by material bed compression and classic ball mill grinding is carried out. Comminution experiments were carried out in a laboratory scale piston press, to achieve material bed compression like in HPGR technology, and in a conventional industrial scale ball mill for particle-particle, particle-grinding media interaction. The results showed that the products of the two comminution methods have a significant difference both in particle size and shape distribution.
\end{abstract}

Keywords: Comminution, Material bed compression, Ball mill, WFA

\section{Introduction}

During the last decades, due to the extraordinarily energy intensive processes of raw material preparation industry, the conventional comminution and classification processes have been studied to decrease the energy requirements to reduce the environmental impact and save money. To meet this request from the side of the manufacturing, the High-Pressure Grinding Roll technology has been studied and developed during the last 35 years (Heinicke et al). The dry comminution process by HPGR came into the view firstly at 1980s in Germany and the basis of the technology were almost defined by this time (Schönert, 1966). The main phenomenon of the HPGR comminution is the particle-particle interaction inducted breakage. The particles of the disperse system are feed to the active comminution zone of the HPGR, where the material bed is stressed by two rotating rollers with the motion to opposite direction. The main difference from the conventional roller crusher is the horizontally applied high pressure, that causes a highly energy efficient comminution, and high yield of finer particles. In terms of energy utilization, the 
most efficient comminution is the single particle breakage by compression loading, the second one is the loading by stress the bed of particles, and then the unconfined particle-bed comminution (Schönert,1979). The firstly mentioned single particle breakage is barely can be carried out continuously in operation process. The loading stress on a bed of particles can be achieved by HPGRs and the unconfined particle-bed comminution by ball mills. In industrial environment, HPGRs were used foremost at the cement industry in the related raw material preparation and for the product's dry comminution, where the energy saving was critical part of the production cost, and the higher degree of energy utilization was welcomed by the low and medium added value cement products (Camalan et al., 2016). Due to the successful applications in the cement industry, the technology came to the focus of the mining industry and mineral raw material processing, such as diamond, copper, gold, and iron ore comminution (Abazarpoor et al., 2018) (Anticoi et al., 2018) (Schönert, 1988) (Yin et al., 2017). Nonetheless for the HPGR applications, to the aforementioned ore comminution, was a difficult problem that had to be solved before these machines could use widely in industrially steps, what is the common and sever wear on the roller's mantle by the abrasive ores. To avoid the negative consequences from comminution of more abrasive ores, the roller's mantle design was studied, and the mainly widespread and conventionally applied stud system were concluded as an optimal option to reduce wear (Nagataa et al 2020). The active comminution zone of the rollers can be also increased by the smaller studs, while the stress forces can be also increased, that can cause finer product and a higher comminution ratio (Nagataa et al 2020), but the more friction due to the higher acting forces have a remarkable wear too. The improving materials and molding technology, and the optimal stud system on the roller's surface, could build up a fine material bed too, that lead to a lower wear due to the autogenous comminution on the rollers. In a comparison with ball mills, the major benefits of HPGR's are for various types of minerals, the better energy utilization, less selective crushing of coarse particles and improved mineral liberalization from the ores (Ballantyne et al., 2018) (Liu et al., 2017)]. Generally, it can be stated, the most widespread technology is the hybrid comminution (where the is HPGR technology even known), to achieve the best energy utilization and particle size reduction ratio, because the HPGRs are more efficient at lower energy inputs, and the ball mill is more efficient at higher energy inputs. The systematic experiments were carried out to examine the energy efficiency of the comminution for a HPGR-Ball Mill system and the result has shown to achieve a reduction ratio of 30 , costs only $70 \%$ of the energy input than, to use only a single ball mill (Fuerstenau et al., 1997). The properties of the corundum product for laminate industry produced by comminution and classification processes should meet strict specifications. For Example, particle size should be in the range of 50-150 $\mu \mathrm{m}$, and bulk density should have a minimum value of $1,65 \mathrm{~g} / \mathrm{cm}^{3}$. In this article the particle size distribution and particle shape distribution, which influences the bulk density strongly, of the ground material produced by material bed compression and ball milling are investigated.

\section{Materials and methods}

White fused alumina (WFA) is an excellent high-tech advanced abrasive material with a high additional value for miscellaneous applications on industrial fields like, medical, and dental technology, space and aerospace industry, optical industry, laminate industry. The average and low additional value application fields, like a refractory mineral and sand blasting or polishing agent should be mentioned as well, because those fields use a big quantity of WFA and has a major part of the global market too. The basic of the technology to produce the WFA is the different type of electrical arc furnace, where the metallurgically pure $(\min 98,5 \%) \mathrm{Al}_{2} \mathrm{O}_{3}$ containing alumina melted at $2040{ }^{\circ} \mathrm{C}$. 


\subsection{White Fused Alumina (WFA)}

After the melting of the metallurgically pure alumina with a chemical composition and properties described at Table 1 and 2., in the electric arc furnace at $2040{ }^{\circ} \mathrm{C}$, with a specific smelting work of 1,2 $\mathrm{MWh} / \mathrm{t}$, the melted WFA is casted into the mold and after the solidification is over by the loss of heat, it is crushed by jaw crusher to $0-100 \mathrm{~mm}$ fraction, then the roller crusher comminution results a $0-3 \mathrm{~mm}$ fraction that is classified by sieves to the requested fraction. For the experiments, the pre-crushed $0-3$ $\mathrm{mm}$ fraction was classified to $1-3 \mathrm{~mm}$ fraction with a particles size distribution defined at Figure 1, the fraction has a bulk density of $1,84 \mathrm{~g} / \mathrm{cm}^{3}$. The comminution was carried out in an industrial scale ball mill and in a piston press. Sample materials are from the Refra-System Ltd.

Table 1. Typical chemical content of the metallurgical grade alumina by Alumina d.o.o.Zvornik (https://www.aluminazv.ba/en/category-products/8)

\begin{tabular}{|c|c|c|}
\hline & Typical content [\%] & Guaranteed limits [\%] \\
\hline $\mathrm{Al}_{2} \mathrm{O}_{3}$ & $98,8-99$ & $\min 98,7$ \\
\hline $\mathrm{SiO}_{2}$ & $0,005-0,010$ & $\max 0,015$ \\
\hline $\mathrm{Fe}_{2} \mathrm{O}_{3}$ & $0,008-0,012$ & $\max 018$ \\
\hline $\mathrm{Na}_{2} \mathrm{O}_{\text {total }}$ & $0,3-0,35$ & $\max 0,03$ \\
\hline $\mathrm{CaO}$ & $0,018-0,025$ & $\max 0,0009$ \\
\hline $\mathrm{P}_{2} \mathrm{O}_{5}$ & $0,0002-0,0005$ & $\max 0,003$ \\
\hline $\mathrm{TiO}_{2}$ & $0,002-0,0027$ & $\max 0,022$ \\
\hline $\mathrm{ZnO}$ & $0,017-0,02$ & $\operatorname{man}$ \\
\hline
\end{tabular}

Table 2. Specification of the metallurgical grade alumina by Alumina d.o.o.Zvornik (https://www.aluminazv.ba/en/category-products/8)

\begin{tabular}{|c|c|c|}
\hline & Typical range & Guaranteed limits \\
\hline Specific Surface Area BET & $75-90\left[\mathrm{~m}^{2} / \mathrm{g}\right]$ & $\min 70\left[\mathrm{~m}^{2} / \mathrm{g}\right]$ \\
\hline Bulk Density & $1000-1050\left[\mathrm{~kg} / \mathrm{m}^{3}\right]$ & $\operatorname{max~} 1070\left[\mathrm{~kg} / \mathrm{m}^{3}\right]$ \\
\hline Loss of ignition $\left(300{ }^{\circ} \mathrm{C}-1000{ }^{\circ} \mathrm{C}\right)$ & $0,6-0,9[\%]$ & $\max 1[\%]$ \\
\hline Angle of repose & $32-34\left[{ }^{\circ}\right]$ & $\min 85[\%]$ \\
\hline+45 microns (wet sieve) & $88-95[\%]$ & $\max 2,5[\%]$ \\
\hline-20 microns (wet sieve) & $1-2[\%]$ & \\
\hline
\end{tabular}

\subsection{Industrial scale ball mill}

The dry comminution in the industrial scale ball mill was examined during continuous operation at Refra-System Ltd. Some major parameter of the ball mill such as geometry, power supply, mass flow, etc. are defined at Table 3.

The discharge has perforated holes at the cylinder's end wall, where the product can leave the active grinding zone of the mill, then the rotation of mill and the lifting lamellas discharging the product. The undersized particles, below $45 \mu \mathrm{m}$ are not desired in the product, because of the afterward processing steps, so the particles smaller than $45 \mu \mathrm{m}$ are classified by airflow through a dust cyclone and bag filter. 
Table 3. Geometrical and operating parameters of the industrial scale ball mill

\begin{tabular}{|c|c|}
\hline Internal diameter & $2000 \mathrm{~mm}$ \\
\hline Internal length & $4500 \mathrm{~mm}$ \\
\hline Lining thickness on sidewalls & $30 \mathrm{~mm}$ \\
\hline Lining thickness on cylinder & $5 \mathrm{~mm}$ \\
\hline Material of linings & White rubber \\
\hline Feed opening diameter & $650 \mathrm{~mm}$ \\
\hline Discharge opening diameter & $650 \mathrm{~mm}$ \\
\hline Installed motor power & $75 \mathrm{~kW}$ \\
\hline Feed rate & $3000 \mathrm{~kg} / \mathrm{h}$ \\
\hline
\end{tabular}

\subsection{Laboratory scale piston press}

The laboratory hydraulic piston press was built by the Institute of Raw Material Preparation and Environmental Processing, University of Miskolc for briquetting. Two pistons are situated in the equipment, only one for the pressing force transmission, the other's role is the sample discharge. The hydraulic pressure can be adjusted to 2750 bar by the piston's oil pressure as a maximum value. The pressing velocity can be also adjusted until $34,5 \mathrm{~mm} / \mathrm{s}$. Table 4 shows the technical data of the machine's parameters during the measurements.

Table 4. Geometrical and operating parameters of the laboratory scale piston press

\begin{tabular}{|c|c|}
\hline Diameter of the piston & $25 \mathrm{~mm}$ \\
\hline Piston velocity & $34,5 \mathrm{~mm} / \mathrm{s}$ \\
\hline Pressure at Ø25 mm piston & $2750 \mathrm{Bar}$ \\
\hline Material bed height & $20 \mathrm{~mm}$ \\
\hline
\end{tabular}

\subsection{Measurements of the ground material's particle size and shape distribution}

The particle size measurement and the particle shape analysis were carried out by a RETSCH CAMSIZER X2 device, that is a high performance, extremely versatile laboratory instrument to determine multifarious dispersity properties. The device has a measurement range of 0,8-8000 microns at particle size analysis for dry and wet mode too. The basic principle of the apparatus is the Dynamic Image Analysis, that carried out by the ZOOM for fine particles and BASIC camera for the coarser particles. The device creates a dispersed particle stream, then the high-resolution system, with the two cameras simultaneously, take 300 pictures/s while the software evaluates on time, then summarize it after all the particles have been measured. During measurements, dry mode was applied. The abrasive industry conventionally uses laboratory sieve tests to determine the particle size distribution above 45 microns. The most comparable measurement with CAMSIZER X2 to the sieve analysis, is the determination of Xc min parameter, so during the measurements, this parameter was applied to determine the particle size distribution. The chord Xc is determined, which is defined as the maximum distance between two boundary points perpendicular to the scanning direction. Xc min shows the particle width, which is determined from the narrowest of all measured chords Xc. 


\section{Results}

The particle size distribution function of the input WFA 1-3 mm and the ground particles, also the density function of the products were calculated. To the better comparability of the products the transformed particles size distribution and density function of the material bed compression were created by reducing the functions to the particle size's interval of the ball mill product. The sphericity values and the fault area of sphericity were defined, based on particle volume and particle number.

\subsection{Particles size distribution}

The comparative representation of the feed material and the produced particles by comminution are shown in Figure 1. It can be seen, as the literature stated (Fuerstenau et al, 1997), the higher reduction ratios are specific of the ball mill at high energy input, while the material bed comminution, like in HPGR has lower reduction ratio.

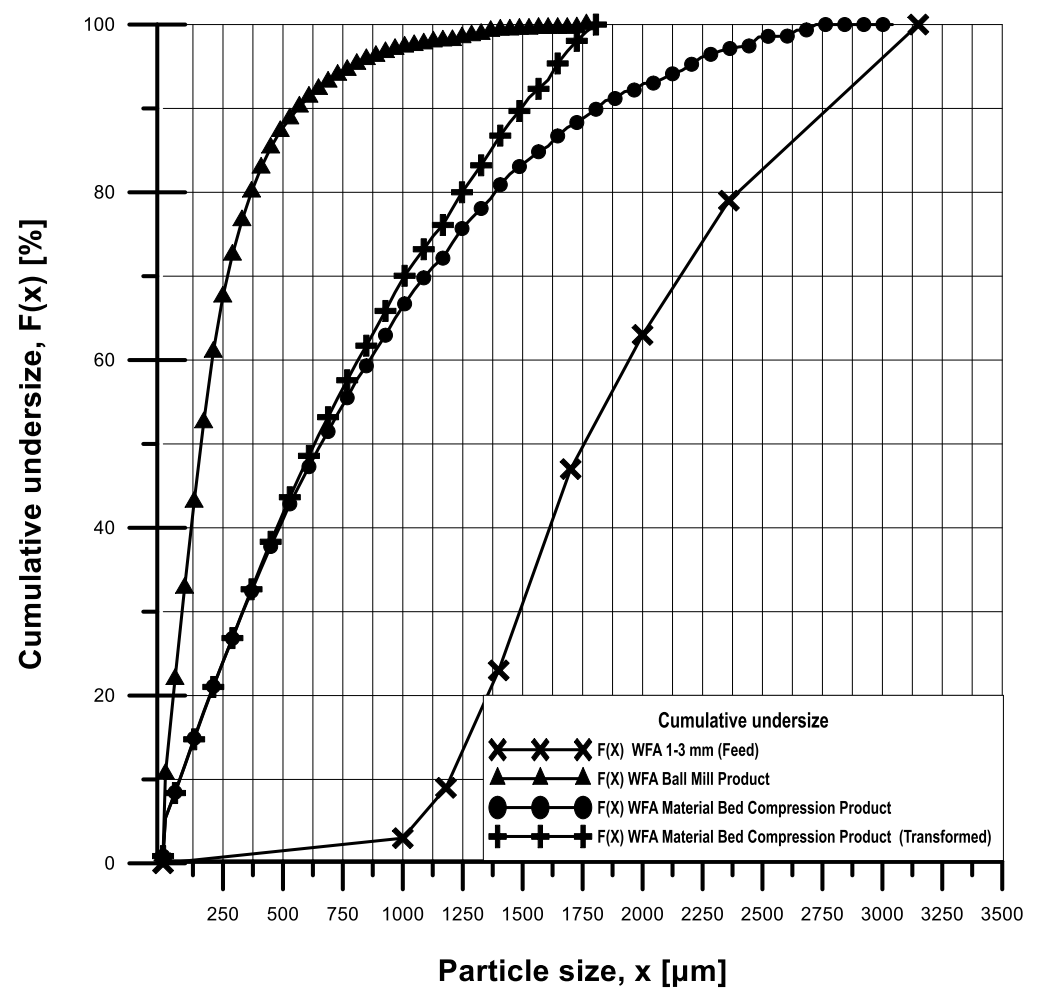

Figure 1. Particle size distribution of the feed 1-3 $\mathrm{mm}$ WFA and the products of material bed compression and ball milling.

According to the ball mill's higher reduction ratio, the particle size distribution function of the ground material by ball mill has a steeper slope, means a narrower function. The maximal particle size of ball mill product is around $1700 \mu \mathrm{m}$, and $97 \%$ is under $1 \mathrm{~mm}$, which means that a very low number of uncomminuted particles are in the product. In case of ball mill, from the 1-3 $\mathrm{mm}$ fraction $88 \%$ of the desired 0-0.5 mm were produced, however the over ground particles with diameter smaller than $50 \mu \mathrm{m}$, in case of the ball mill product were $9,74 \%$ and $5,43 \%$ for the material bed compression. The product of the material bed compression has significantly different particle size distribution than the ball mill's 
one. The distribution is much wider, the maximal particle size is $3000 \mu \mathrm{m}$, the ratio of the desired 0-0.5 $\mathrm{mm}$ product is only $42 \%$, but this comminution method created significantly less fine, $<50 \mu \mathrm{m}$ particles.

\subsection{Particles size density function}

The ball mill produced particles have a monomodal density function, while the material bed compression's product has a wider range of function, that is also a consequence of the lower comminution ratio, can be seen at Figure 2 . The tendency of the density function at the material bed compression's product is an increasing one, while the particle size is decreasing. The finest, $<10 \mu \mathrm{m}$ particles can make the air classification significantly more difficult as they stick to the surface of the bigger particles, so their amount in the product could be important. The ball mill product's has $0,91 \%$, while the material bed compression product's $0,86 \%$ of $<10 \mu \mathrm{m}$ particles. The Figure 2 shows that the ball mill and the material bed compression experiments resulted a different types of density functions, the ball mill has a more concentrated and finer product, while the material bed compression has a steadier one, on wider particle size interval.

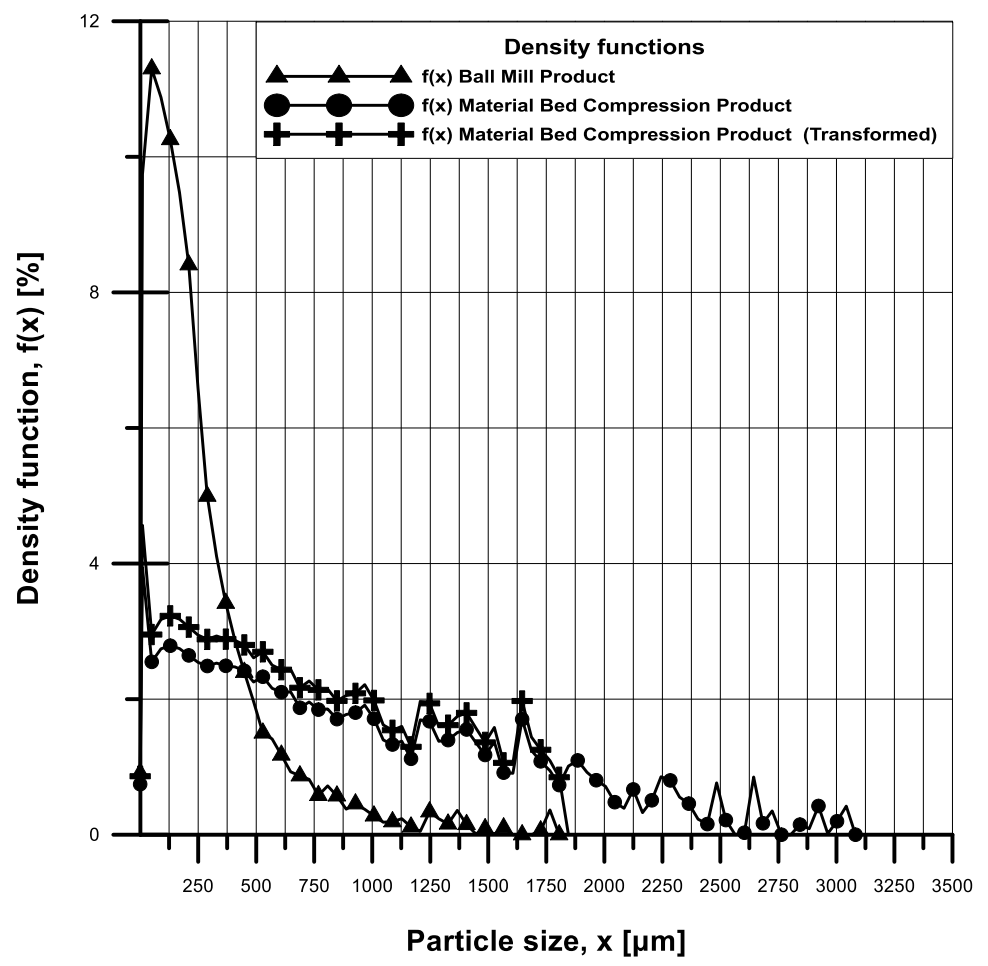

Figure 2. Particle size density functions of the WFA products of material bed compression and ball mill.

\subsection{Sphericity of particles}

The sphericity parameter displays the roundness and the deviation from the perfect circle or sphere, where the value of sphericity equal 1 , in case of the perfect sphere and every different particle shape has a lower value than 1 . The sphericity of the produced particles is a function of the different types of stresses acting, during the comminution processes. The comminution process's working principles and 
their effects on output particle's shapes can be seen on the Figure 3. The ball mill's attrition and impact stress increase the sphericity of the product, while the material bed compression and its compression stress cause lower sphericity in the product. The material bed compression product has a lower average sphericity value over the whole $0-1 \mathrm{~mm}$ particle size interval, but the tendency is increasing with a decreasing particle size. The ball mill particles have an unsteady sphericity at the interval of $0,5-1 \mathrm{~mm}$ particle size, but under $0,5 \mathrm{~mm}$, the particles of the fraction have an increasing tendency of sphericity value. It can be also seen, the sphericity reached the maximum values at the particle size interval of 100200 micron, in both products.

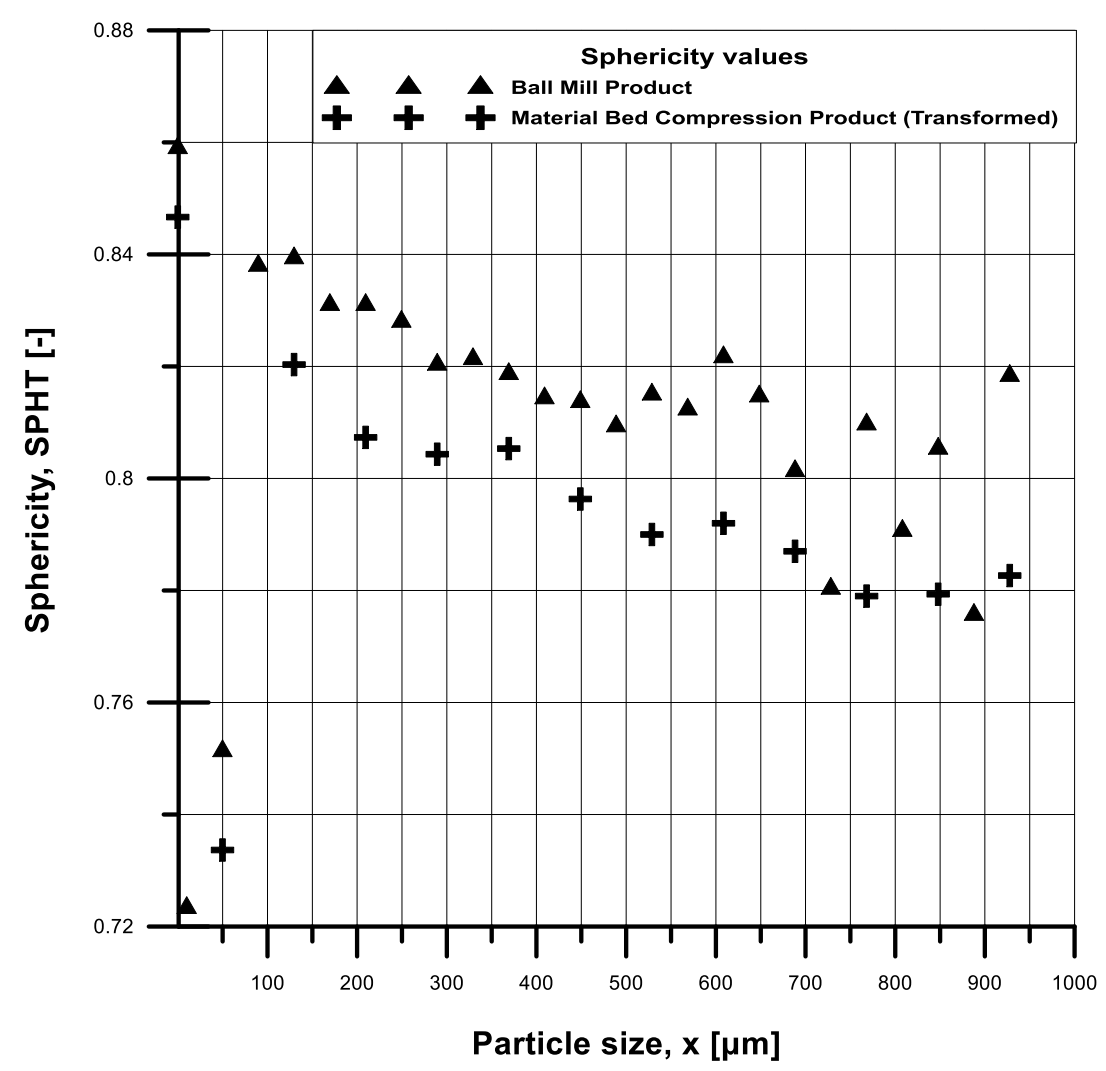

Figure 3. Sphericity of size fractions of material bed compression and ball milling.

\subsection{Particle shape distribution function based on the sphericity}

The sphericity-based particle shape distribution measurement on the comminuted fractions were carried out based on particle number. The results of the particle shape distribution function based on the sphericity can be seen at Figure 4. Also, the SPHT value of 1, has the perfect roundness and spherical particle shape and it can be seen at the SPHT value of 0,9-1 interval of the measurement, the ball mill product has a more spherical particle shape. The proportion of the particles with a smaller than 0,8 SPHT value is $12,6 \%$ at the ball mill product and $15,5 \%$ at the material bed compression product. This SPHT value shows a blocky and not spherical particle shape. The stress environment in the ball mill, that related to the comminution by grinding media, has an advantageous attribution to produce particles with higher sphericity values due to the simultaneously appearing collisions and attrition between the 
particles and grinding media, while the comminution by particle bed compression creates less spherical particle shape.

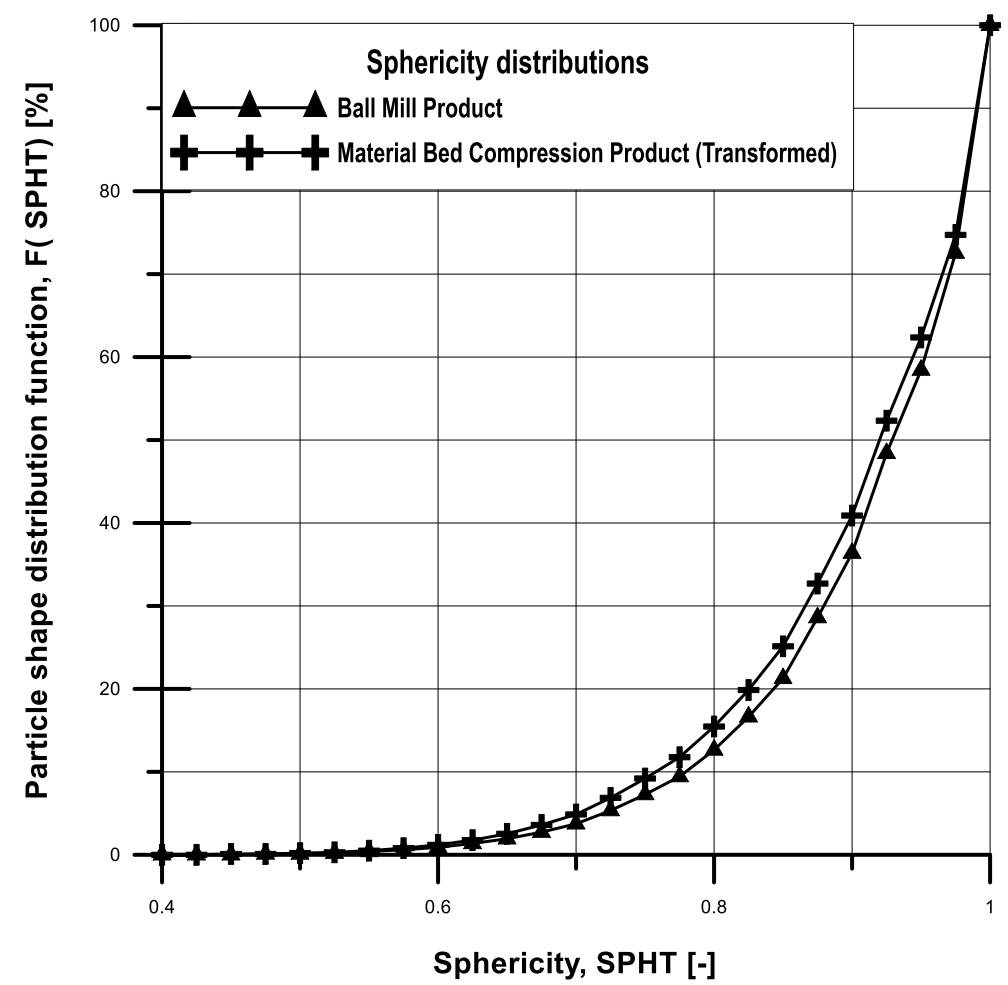

Figure 4. Particle number based WFA product's sphericity of material bed compression and ball mill.

\section{Summary}

Comminution experiments were carried out, to examine the produced particle size and shape distribution of WFA products by different comminution methods, like ball milling and material bed compression. According to the current knowledge of the literature, the lower comminution ratio was also shown with the HPGR's like stress generated by laboratory scale piston press. The quantity of the fine particles was defined, and the material bed compression product had a lower quantity of fine fraction, even the ball mill product is classified by the continuous airflow to separate this fraction and decrease it to the lowest possible level. The over-ground particles with a size $<50$ microns, in case of the ball mill product were $9,74 \%$ and $5,43 \%$ for the material bed compression. The results showed no significant, but obvious difference in the particle number-based particle shape distribution function, with more spherical particles in the ball mill product. A major difference was pointed out on the size fraction's sphericity values as the material bed compression product has a significantly lower sphericity values over the whole $0-1 \mathrm{~mm}$ particle size interval and the tendency is increasing with a decreasing particle size. The sphericity reached the maximum values at the particle size interval of 100-200 $\mu \mathrm{m}$, in both produced fractions. After the basic experiments, it can be stated, that the comminution by material bed compression produces less fines, but the particle shape is less spherical than the ball milled WFA. Further experiments are planned for the better understanding of the material bed compression comminution's principles and peculiarities. 


\section{Acknowledgements}

Prepared with the professional support of the Doctoral Student Scholarship Program of the Co-operative Doctoral Program of the Ministry of Innovation and Technology financed from the National Research,

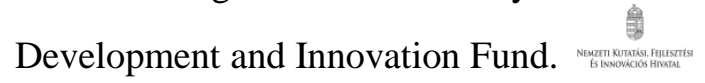

\section{References}

[1] Heinicke, F., Günter, H., Lieberwirth, H. Modelling of HPGR Edge recycling with progressive grinding data

[2] Schönert, K. (1966). Einzelkorn-Druckzerkleinerung und Zerkleinerungskinetik. Untersuchungen an Kalkstein-, Quarz-, und Zementklinkerkörnern des Größenbereiches 0,1$0,3 \mathrm{~mm}$. Dissertation. TH Karlsruhe.

[3] Schönert, K. (1979). Zement-Kalk-Gips Int. 32, 1.

[4] Camalan, M., Önal, M. A. R. (2016). Influence of high-pressure grinding rolls on physical properties and impact breakage behavior of coarsely sized cement clinker. Part. Sci. Technol., 34, 278-288. https://doi.org/10.1080/02726351.2015.1075636

[5] Fuerstenau, D. W., Kapur, P. C., Schönert, K., Marktscheffel, M. (1990). Comparison of energy consumption in the breakage of single particles in a rigidly mounted roll mill with ball mill grinding. Int. J. Miner. Process., 28, 109-125. https://doi.org/10.1016/0301-7516(90)90030-3

[6] Abazarpoor, A., Halali, M., Hejazi, R., Saghaeian, M. (2018). HPGR effect on the particle size and shape of iron ore pellet feed using response surface methodology. Miner. Process. Extr. Metall. Trans. Inst. Min. Metall., 127, 40-48. https://doi.org/10.1080/03719553.2017.1284414

[7] Anticoi, H., Guasch, E., Hamid, S., Oliva, J., Alfonso, P., Garcia-Valles, M., Bascompta, M., Sanmiquel, L., Escobet, T., Argelaguet, R., Escobet, A., de Felipe, J. J., Parcerisa, D., PeñaPitarch, E. (2018). Breakage function for HPGR: Mineral and mechanical characterization of tantalum and tungsten ores. Minerals, 8, 170. https://doi.org/ 10.3390/min8040170

[8] Schönert, K. (1988). A first survey of grinding with high-compression roller mills. Int. J. Miner. Process., 22, 401-412. https://doi.org/10.1016/0301-7516(88)90075-0

[9] Yin, W., Tang, Y., Ma, Y., Zuo, W., Yao, J. (2017). Comparison of sample properties and leaching characteristics of gold ore from jaw crusher and HPGR. Miner. Eng., 111, 140-147. https://doi.org/10.1016/j.mineng.2017.06.012

[10] Nagataa, Y., Tsunazawab, Y., Tsukadac, K., Yaguchid, Y., Ebisue, Y., Mitsuhashie, K., Tokorof, C. (2020). Effect of the roll stud diameter on the capacity of a high-pressure grinding roll using the discrete element method. Miner. Eng., 154. https://doi.org/10.1016/j.mineng.2020.106412

[11] Ballantyne, G. R., Hilden, M., van der Meer, F. P. (2018). Improved characterisation of ball milling energy requirements for HPGR products. Miner. Eng., 116, 72-81. https://doi.org/10.1016/j.mineng.2017.06.005

[12] Liu, Lei, Tan, Q., Liu, Lu., Li, W., Lv, L. (2017). Comparison of grinding characteristics in highpressure grinding roller (HPGR) and cone crusher (CC). Physicochem. Probl. Miner. Process., 53, 1009-1022. https://doi.org/10.5277/ppmp170226

[13] Fuerstenau, D. W., Vazquez-Favela, J. (1997). Miner. Metall. Process., 11, 41. https://doi.org/10.1007/BF03402750

[14] Manual Evaluation Software CAMSIZER $® ~ X 2$

[15] https://www.aluminazv.ba/en/category-products/8, downloaded: 07.2021. 